Supporting information

\title{
Online extraction Coupled to Liquid Chromatography Analysis (OLE-LC): Eliminating Traditional Sample Preparation Steps in the Investigation of Solid Complex Matrices
}

Vinícius G. Ferreira $^{1}+$; Gabriel M. Leme ${ }^{1}+$; Alberto J. Cavalheiro ${ }^{1 *}$; Cristiano S. Funari $^{2,3}$

${ }^{1}$ Chemistry Institute, São Paulo State University (UNESP), 14800-900 Araraquara, São Paulo, Brazil.

${ }^{2}$ College of Agricultural Sciences, São Paulo State University (UNESP), Private Bag 237, Botucatu 18610-307, São Paulo, Brazil.

${ }^{3}$ Australian Centre for Research on Separation Science (ACROSS), School of Physical Sciences, University of Tasmania, Private Bag 75, Hobart 7001, Australia.

$\$$ These authors contributed equally to this work.

Tel.: +55 16 33019791, E-mail: albjcava@gmail.com

Figure S-1 presents three chromatograms obtained sequentially using the OLE-LC approach.

Figure S-2 presents the UV spectra of some representative peaks in Casearia sylvestris fingerprint.

Figure S-3 presents the chromatographic profile of different plant tissues and species.

Table S-1 presents a comparative overview between OLE-LC and known protocols.
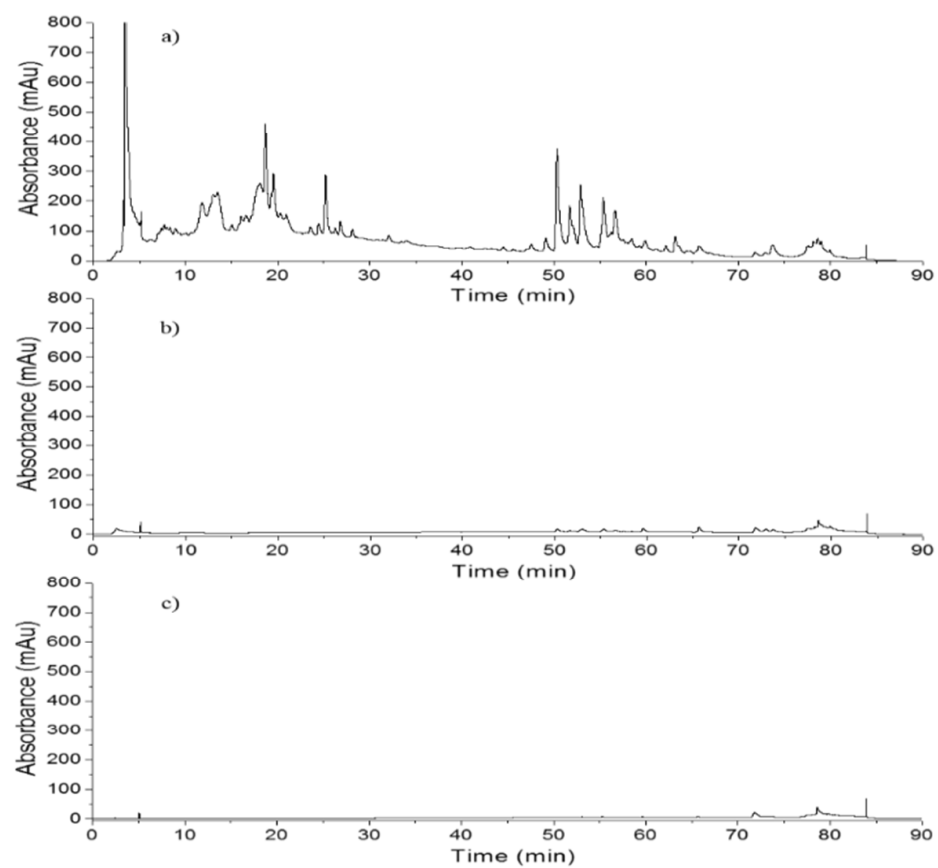

Figure S-1. HPLC-UV fingerprints of leaves of C. sylvestris at $250 \mathrm{~nm}$. Column: Synergi Hydro-RP, $250 \times 4.6 \mathrm{~mm} ; 4$ $\mu \mathrm{m}$. Mobile-phase: $\mathrm{H} 2 \mathrm{O}$ and $\mathrm{EtOH}: 2.7-83.7 \%$ of EtOH for $61.8 \mathrm{~min}$, followed by $10 \mathrm{~min}$ in isocratic mode, posteriorly $10 \mathrm{~min}$ in isocratic mode of $100 \%$ of EtOH was used to ensure the cleaning of the system. Flow rate: 0.7 $\mathrm{mL} / \mathrm{min}$. Samples: a) First extraction of $2 \mathrm{mg}$ of dry ground material; b) second sequential extraction of the same material and c) third sequential extraction. 


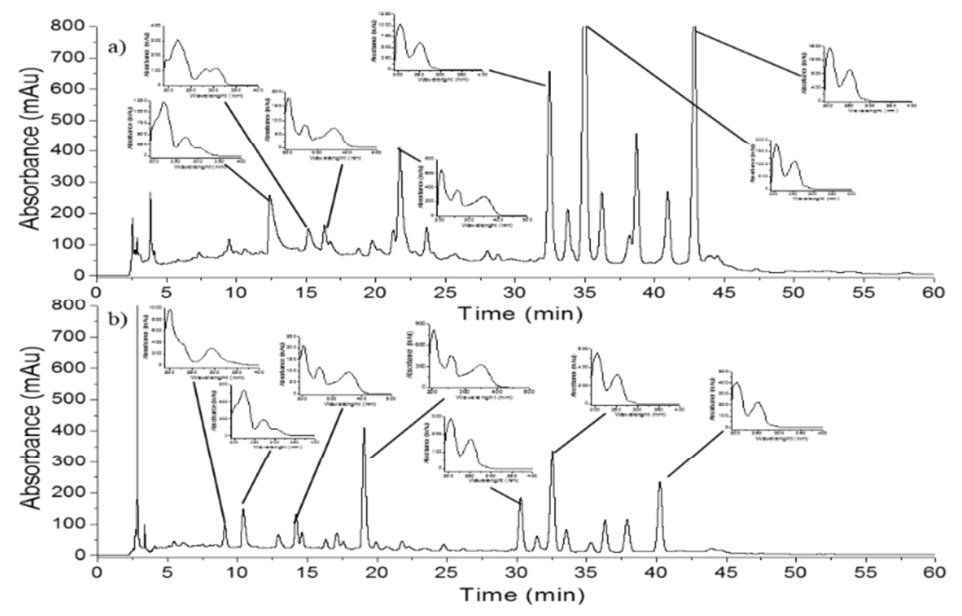

Figure S-2. HPLC-UV fingerprints of leaves of $C$. sylvestris at $250 \mathrm{~nm}$ showing UV spectra of the peaks. Column: Synergi Hydro-RP, $250 \times 4.6 \mathrm{~mm} ; 4 \mu \mathrm{m}$. Mobile phase: $\mathrm{H}_{2} \mathrm{O}$ and EtOH: $2.7-83.7 \%$ of B (0-61.8 min); 83.7\% of B (61.8-90 min). Flow rate: $0.7 \mathrm{~mL} / \mathrm{min}$. Samples: a) $2 \mathrm{mg}$ of the dry ground leaves and b) $20 \mu \mathrm{L}$ of a $20 \mathrm{mg} / \mathrm{mL}$ extract solution (corresponding to $3.0 \mathrm{mg}$ of the original dry ground leaves).

a)
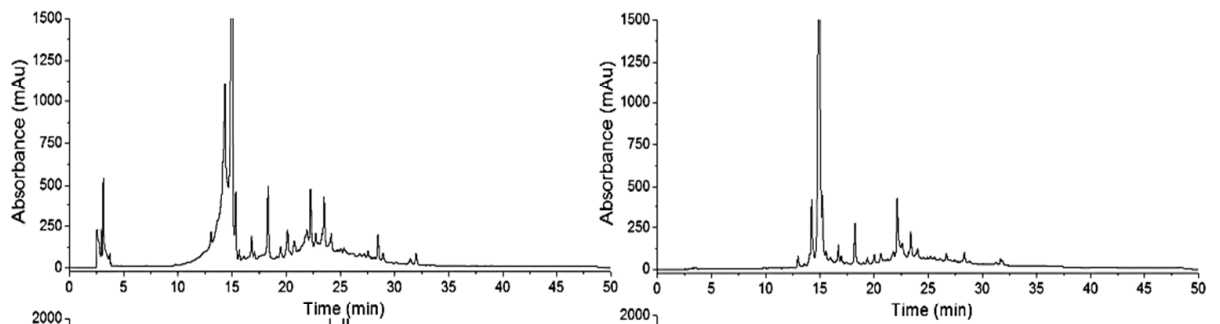

b)
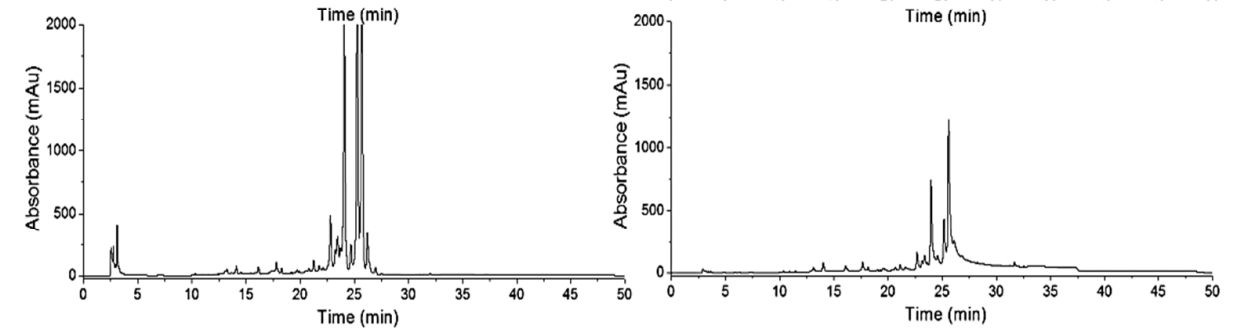

Figure S-3. HPLC-UV fingerprints of different species and tissues at $250 \mathrm{~nm}$. Column: Phenomenex Luna C18, $250 \times 4.6 \mathrm{~mm} ; 5 \mu \mathrm{m}$. Mobile-phase: $\mathrm{H}_{2} \mathrm{O}$ and $\mathrm{MeOH}: 5 / 5 / 100 / 100 \%$ B in 0/5/30/40 min. Flow rate: $0.7 \mathrm{~mL} / \mathrm{min}$. Samples: a) steams of Tocoyena formosa and b) seeds of Pterogyne nitens. Left chromatograms: $20 \mu \mathrm{L}$ (corresponding to $0.08 \mathrm{mg}$ ) of a $40 \mathrm{mg} / \mathrm{mL}$ extract and right chromatograms: $2 \mathrm{mg}$ of the dry ground material. 
Table S-1. Comparative overview between OLE-LC and known protocols in which typical sample preparation steps were integrated with HPLC analysis.

\begin{tabular}{|c|c|c|c|c|c|c|c|c|c|c|c|c|}
\hline $\begin{array}{l}\text { Protocol } \\
\text { reference }\end{array}$ & $\begin{array}{l}\text { Solid } \\
\text { matrix } \\
\text { sample }\end{array}$ & $\begin{array}{l}\text { Drying of } \\
\text { the collected } \\
\text { material }\end{array}$ & Grinding & $\begin{array}{l}\text { Solvent used } \\
\text { for extraction } \\
\text { only }\end{array}$ & $\begin{array}{l}\text { Fluid extract } \\
\text { filtration or } \\
\text { centrifugation }\end{array}$ & $\begin{array}{l}\text { Solvent } \\
\text { elimination }\end{array}$ & $\begin{array}{l}\text { Solid phase } \\
\text { extraction }\end{array}$ & Eluate drying & $\begin{array}{l}\text { Residue } \\
\text { solubilization }\end{array}$ & $\begin{array}{l}\text { Filtration in } \\
\text { a } \mu \mathrm{m} \text { filter }\end{array}$ & $\begin{array}{l}\text { Number of } \\
\text { additional } \\
\text { valve(s) }\end{array}$ & $\begin{array}{l}\text { Number of } \\
\text { additional } \\
\text { pump(s) }\end{array}$ \\
\hline OLE-LC & Yes & No & No & No & No & No & No & No & No & No & 0 & 0 \\
\hline 11 & No & N.a. & N.a. & Yes & Yes & Yes & No & Yes & Yes & Yes & 0 & 0 \\
\hline 12 & Yes & Yes & Yes & Yes & No & Yes & Yes (online) & No & No & No & 3 & 0 \\
\hline 13 & Yes & No & No & Yes & No & No & Yes (online) & No & No & No & 1 & 2 \\
\hline 14 & No & N.a. & N.a. & No & Yes & No & No & No & No & No & 1 & 1 or 2 \\
\hline 15 & No & N.a. & N.a. & No & Yes & No & No & No & No & No & 1 & 1 or 2 \\
\hline 17 & No & N.a. & N.a. & Yes & Yes & No & Yes (online) & No & No & No & 0 & 1 \\
\hline 18 & No & N.a. & N.a. & Yes & Yes & No & No & No & No & No & 0 & 1 \\
\hline 19 & No & N.a. & N.a. & No & No & No & Yes (online) & No & No & No & 1 & 1 \\
\hline \multicolumn{13}{|c|}{$\begin{array}{l}{ }^{1} \text { Please, refer to references in the main text } \\
\text { N.a.: not apply }\end{array}$} \\
\hline
\end{tabular}

Page S-3 